\title{
Effect of headspace gas on nucleation of amorphous paracetamol
}

\author{
Palomäki, Emmi A. K.
}

2019-06

Palomäki , E A K , Yliruusi , J K \& Ehlers , H 2019 , ' Effect of headspace gas on nucleation of amorphous paracetamol ', Journal of Drug Delivery Science and Technology , vol. 51 , pp. 127-138 . https://doi.org/10.1016/j.jddst.2019.02.019

http://hdl.handle.net/10138/312183

https://doi.org/10.1016/j.jddst.2019.02.019

cc_by_nc_nd

acceptedVersion

Downloaded from Helda, University of Helsinki institutional repository.

This is an electronic reprint of the original article.

This reprint may differ from the original in pagination and typographic detail.

Please cite the original version. 


\section{Accepted Manuscript}

Effect of headspace gas on nucleation of amorphous paracetamol

Emmi A.K. Palomäki, Jouko K. Yliruusi, Henrik V. Ehlers

ap a A I I

PII:

S1773-2247(18)31548-X

DOI:

https://doi.org/10.1016/j.jddst.2019.02.019

Reference:

JDDST 946

To appear in: Journal of Drug Delivery Science and Technology

Received Date: 16 January 2019

Revised Date: 6 February 2019

Accepted Date: 19 February 2019

Please cite this article as: E.A.K. Palomäki, J.K. Yliruusi, H.V. Ehlers, Effect of headspace gas on nucleation of amorphous paracetamol, Journal of Drug Delivery Science and Technology (2019), doi: https://doi.org/10.1016/j.jddst.2019.02.019.

This is a PDF file of an unedited manuscript that has been accepted for publication. As a service to our customers we are providing this early version of the manuscript. The manuscript will undergo copyediting, typesetting, and review of the resulting proof before it is published in its final form. Please note that during the production process errors may be discovered which could affect the content, and all legal disclaimers that apply to the journal pertain. 

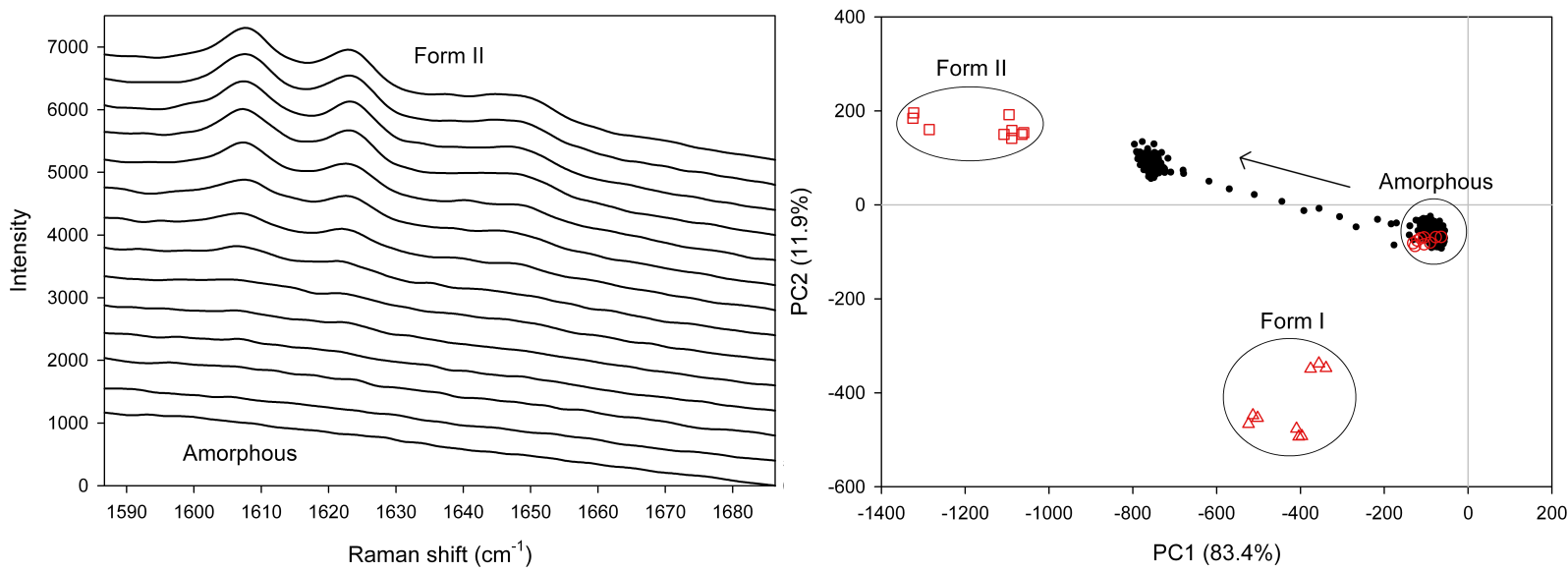

Crystallization of amorphous paracetamol to form II in dry air atmosphere, at $21.8-21.9^{\circ} \mathrm{C}$. 


\title{
Effect of headspace gas on nucleation of amorphous paracetamol
}

\author{
Emmi A.K. Palomäki ${ }^{*}$, Jouko K. Yliruusi ${ }^{1}$, Henrik V. Ehlers ${ }^{1}$
}

1) Faculty of Pharmacy, P.O. Box 56, FI-00014 University of Helsinki, Finland

*email: emmi.palomaki@helsinki.fi

\section{Abstract}

In this paper, the effect of the gaseous environment on recrystallization of amorphous paracetamol was investigated. The experiments were conducted with a headspace gas consisting of dry air, dry carbon dioxide, dry nitrogen and humid air in four temperatures ranging from $5{ }^{\circ} \mathrm{C}$ below onset of $T_{g}$ to $5{ }^{\circ} \mathrm{C}$ above onset of $T_{g}$. The recrystallization was monitored using Raman spectroscopy and subsequent multivariate analysis. In temperatures below onset of $T_{g}$, the presence of oxygen delayed the onset of recrystallization, with an increasing delay with lower temperature. When comparing samples exposed to dry headspace gases, the crystallization was fastest below onset of $T_{g}$ when exposed to nitrogen. Being an inert gas, nitrogen did not seem to interfere with the molecules allowing them to freely find their inherent arrangement, whereas the presence of oxygen delayed the formation of stabile nuclei. Above onset of $T_{g}$, no differences in onset of crystallization was detected between dry gas atmospheres. Amorphous paracetamol crystallized to form II in all measurements and the samples did not reach full crystallinity within the duration of the experiments. The results show that the headspace gas has an effect on nucleation in the amorphous sample.

Chemical compounds studied in this article: Paracetamol (PubChem CID 1983)

Key words: Amorphism, Crystallization, Nucleation, Raman spectroscopy, Sorption, Paracetamol

\section{Introduction}

Solubility issues are an increasingly important challenge in drug development, as most new chemical entities suffer from insufficient water solubility, which is a severe limitation in medical applications.[1,2] Dissolution of the active ingredient is a prerequisite in successful drug therapy, since only dissolved drug molecules interact with their target receptors. Sufficient aqueous solubility enables therapeutically relevant concentrations of drug to be reached in the gastro-intestinal tract, which is a prerequisite for absorption, distribution and, in the end, the desired therapeutic effect.

Poor aqueous solubility can be remedied through salt formation, using prodrugs, particle size reduction or rendering the material in an amorphous form.[3,4] Amorphous materials have superior kinetic solubility compared to their crystalline counterparts, since they have higher level of molecular disorder, free energy and molecular mobility. Nevertheless, they also tend to revert to their most stabile crystalline form. There has been considerable effort to investigate the nature of amorphous materials and how to maintain the amorphous form. However, the understanding of the crystallization process remains incomplete to date.[5,6]

50 Recrystallization of amorphous material can occur in minutes, but at times the amorphous form can also be maintained for years. Typically, amorphous materials containing small molecules recrystallize faster than those containing big, flexible molecules.[7,8] In recent years, the importance of surface phenomena in the stability and recrystallization of amorphous drug substances has been established and highlighted.[9] Molecular mobility is significantly higher on the surface than in the bulk of amorphous glasses below the glass transition temperature.[9-13] This renders the surface molecules more susceptible to rearrange into crystal lattices than within the bulk. For example, in the case of felodipine, storage temperatures have to be at least $25^{\circ} \mathrm{C}$ above $\mathrm{T}_{\mathrm{g}}$ to achieve equal bulk and surface crystallization rates; below that temperature surface crystallization will dominate over bulk crystallization.[14] Since the onset of crystallization is surfacedriven, one could be inclined to assume that interaction between the molecules of the gas phase and the surface molecules will have an effect on the initiation and progress of recrystallization of amorphous 
substances. Water molecules in the gaseous phase are known to have a great impact on the rate of crystallization of amorphous substances.[15] Water is readily absorbed into amorphous substances, where it acts an effective plasticizer lowering the glass transition temperature, subsequently enabling a significant increase in molecular mobility. As a consequence, the recrystallization rates increase correspondingly.

Still, even though the interaction between molecules in the gaseous and solid phase is known to have an impact on the stability of the amorphous state in the case of water vapor, reports of the impact of other gases on amorphous pharmaceuticals are scarce. Qi et al. [16] and Perrin et al. [17] investigated the effect of nitrogen on the recrystallization of amorphous paracetamol. They found that at a specific temperature, paracetamol crystallized into metastable form III when exposed to a nitrogen atmosphere. One could, on the other hand, conclude that the atmosphere itself does not necessarily induce crystallization of form III, since form III is also formed in samples trapped under glass [18,19] or in a capillary [17] without having any contact to the atmosphere. Byrn et al. [20] reported that amorphous DL-Ala-DL-Met-dipeptide underwent oxidation to an extent of one magnitude more than its crystalline counterpart did. The reason for this may be the higher free volume and greater molecular mobility of amorphous substances compared to crystalline substances. When amorphous indomethacin was subjected to gaseous ammonia, the indomethacin reacted with the gas while still remaining amorphous.[21] Alpha-indomethacin also reacted with ammonia gas, whereas gammaindomethacin did not. The study showed that when the relevant functional group is exposed to the gaseous phase, a reaction between the gaseous phase and the solid may occur. In the case of amorphous samples, the more spacious packing and molecular mobility enable reactions between the gaseous phase and the amorphous surface. These examples suggest that headspace gas may have an effect on crystallization on amorphous pharmaceuticals to a further extent than currently acknowledged.

In the present study, crystallization of amorphous paracetamol was investigated with a primary focus on onset of crystallization. Raman spectroscopy was used for both quantitative and qualitative analysis of the crystalline content in amorphous paracetamol samples prepared and stored in dry air, humid air, dry carbon dioxide and dry nitrogen atmospheres. The aim of the study was to investigate the effect of headspace on crystallization of amorphous paracetamol. Oxygen is known for being a reactive gas, that easily polarizes. As shown by Byrn et al. [20], gaseous oxygen is able to interfere with hydrogen bonding sites of amorphous substances, and therefore it was hypothesized that oxygen could be able to interact and form bonds with amorphous paracetamol, and consequently interfere with the crystallization tendency of amorphous paracetamol. Contrarily, nitrogen was expected to behave in accordance with its inert nature. This study shows that oxygen causes a delay in the onset of crystallization by bonding occasionally with paracetamol, which delays formation of stable nuclei. To our knowledge, this is the first time, when the effect of different headspace gases on the crystallization of an amorphous pharmaceutical was systematically investigated. Earlier, the effect of the gaseous phase on amorphous samples has been a minor part of some studies, but this is the first time multiple different gases are compared in the study with the primary aim of isolating the effects of the gaseous phase on amorphous samples.

\section{Materials and methods}

\subsection{Sample preparation}

In the present study, crystalline paracetamol form I (Orion Pharma, Helsinki, Finland, Ph. Eur. quality) was used as model substance. Paracetamol has $T_{g}$ of $24 \pm 2{ }^{\circ} \mathrm{C}$ depending on thermal history [16], and crystallizes rapidly even in cool temperatures [22]. In our study, onset of $T_{g}$ was $22.3 \pm 0.1$. Determination of $T_{g}$ is described in more detail in chapters 2.2.1 and 3.1.

The samples were prepared in a glove box with a set atmosphere consisting of dry air, nitrogen $\left(\mathrm{N}_{2}\right)$, carbon dioxide $\left(\mathrm{CO}_{2}\right)$ or humid air. As known, dry air consists of several gases, of which nitrogen $(78.1 \%)$, oxygen $(20.9 \%)$, argon $(0.9 \%)$ and carbon dioxide $(0.04 \%)$ are the most prominent ones. The raw material was kept in the selected atmosphere for a minimum of 10 min prior to melting. Cooling the sample and closing the sample holder (Fig. 1) were performed in a glove box with the selected atmosphere.

115 Before preparing the amorphous samples, $10.00 \pm 0.08 \mathrm{mg}$ of crystalline paracetamol (Form I) was placed in the glove box, which was subsequently closed. The selected gas was conducted into the glove box using a pressure of 1.6 bar. When the relative humidity in the glove box reached a stable equilibrium value, the sample was left to acclimatize for some ten minutes. In the measurement of amorphous substances, it must be kept in mind that they are hygroscopic. Consequently, if the measurement is conducted in an environment with deviates from that of dry gas and dry sample, the surface interaction between gas and solid is biased by 
water interacting with the solid surface and gas interacting with water.[23] The equilibrium relative humidity of the gaseous phase in the present study was $4.4-4.7 \%$ for dry air, $1.2-1.5 \%$ for carbon dioxide, $0.0-0.1 \%$ for nitrogen and $21.1-22.2 \%$ for humid air. The sample was melted in situ in the sample holder on a hot plate at $210^{\circ} \mathrm{C}$. The temperature was kept clearly above the melting point of paracetamol to ensure sufficient heat transfer through the sample holder. Because of the heat loss to the sample holder, the effective temperature reaching the sample was approximately $190^{\circ} \mathrm{C}$. The temperature was high enough to allow any residual water escape from the sample during melting. Consequently, the equilibrium humidity of the amorphous samples was determined by the relative humidity of the gaseous atmosphere.

130 To ensure complete melting, the sample was kept on the hot plate for 3.5-4 minutes. The state of complete melting was determined through visual inspection. The sample was cooled down to $15.55 \pm 0.45{ }^{\circ} \mathrm{C}$ in a controlled manner using a cooled metallic block with a temperature of $13.15 \pm 0.25{ }^{\circ} \mathrm{C}$. This was done to minimize the interaction of water with of high-energy regions that may be formed during quench cooling. Martínez et al. [24] reported that very fast cooling of paracetamol can lead to devitrification. The sample holder was sealed with the sample confined in the selected atmosphere. Degradation of sample was not detected after sample preparation, since there was no colour change and in the DSC results melting point of the sample was the same than in reference material. According to Gilpin and Zou [25], degradation would be under $0.2 \%$ in the selected conditions, which can be regarded as reasonably low. All steps of the sample preparation were completed with great attention focused on keeping the process identical between samples, since the thermal history of the sample has been shown to have a significant impact on the crystallization of amorphous paracetamol.[16]

\subsection{Solid-state analysis}

145 To study the solid-state state properties of the amorphous paracetamol, raw material and end products, various methods were employed as depicted in Figure 2 and further described in subsequent sections.

\subsubsection{Differential scanning calorimetry}

150 Samples of bulk paracetamol, freshly prepared amorphous samples and samples of end products were analysed using differential scanning calorimetry (DSC; DSC823e, Mettler-Toledo Inc., Switzerland). The sample sizes were 4.99-5.04 $\mathrm{mg}$. Amorphous samples for differential scanning calorimetry (DSC) measurements were prepared as described above and detached from microscope slide using a scalpel immediately prior to analysis. Crystalline samples were measured after crystallization in temperatures of 18.3

$155{ }^{\circ} \mathrm{C}$ and $28.3^{\circ} \mathrm{C}$. All samples were held in $-20^{\circ} \mathrm{C}$ before initiating the heating cycle. The heating of the samples was conducted from $-20^{\circ} \mathrm{C}$ to $200^{\circ} \mathrm{C}$ with a heating rate of $10^{\circ} \mathrm{C} / \mathrm{min}$.

\subsubsection{Raman spectroscopy}

160 In the present study, a Raman spectrometer was used to allow measurement through the bottom of the sample holder and throughout the entire sample volume. The measurement depth is described in more detail in Palomäki et al [26]. Monitoring the process of recrystallization of amorphous samples using Raman spectroscopy was initiated 10 minutes after completion of sample cooling in all experiments. The measurements were performed through the bottom of the sample holder to maximize measurement repeatability. Raman spectra were collected using a Raman RXN1-PhAT-785-D spectrometer (Kaiser, USA), PhAt system probe head (Kaiser optical systems, Inc, USA), a 400-mW laser source at $785 \mathrm{~nm}$ (Raman RXN1-PhAT-785-D, Kaiser aerospace \& electronics company, USA) and spectral resolution of $0.3 \mathrm{~cm}^{-1}$. The used spectrometer differs from confocal Raman spectrometry by having a wider laser. Typically, the laser beam diameter is under $1 \mathrm{~mm}$, whereas in the PhAT system Raman diameter is $6 \mathrm{~mm}$. Consequently, it saves the sample from heating. The wider laser area also makes the sensitivity to positioning and inhomogeneity of sample smaller. $[27,28]$ Raman spectroscopy can be used to identify and quantify the amorphous-crystalline ratio in the sample $[29,30]$, and has the ability to detect crystalline content down to approximately $1 \%$ [30]. Raman spectroscopy is non-invasive, non-destructive and rapid method, which is suitable for real-time monitoring of amorphous-crystalline transitions.[26,29]

The measurements had an integration time of 0.5 seconds and one measurement was the result of three averaged scans. During the recrystallization experiments spectra were collected with 30 -second intervals in four different temperatures: well below onset of $T_{g}\left(17.2 \pm 0.3^{\circ} \mathrm{C}\right)$, slightly below onset of $T_{g}\left(21.7 \pm 0.2^{\circ} \mathrm{C}\right)$, slightly above onset of $T_{g}\left(23.9 \pm 0.4^{\circ} \mathrm{C}\right)$ and well above onset of $T_{g}\left(27.5 \pm 0.2^{\circ} \mathrm{C}\right)$. 
Reference samples of amorphous, form I and form II were made in triplicate as described by Kauffman et al. [31]. The reference samples were used to confirm the crystallization pathway of amorphous paracetamol. Reference sample containing polymorphic form III were not prepared, since the sample holder and temperature ranges in the present study do not enable formation of form III. Three measurements were conducted on each sample. One measurement was the average of three spectra acquired in a time period of 30 seconds. The spectra were subjected to principal component analysis (PCA). Prior to the analysis, spectra were treated with Savitzky-Golay smoothening (window size $9,3^{\text {rd }}$ degree equation) and $1^{\text {st }}$ derivative. The spectral area selected for PCA was $1586.7-1686.3 \mathrm{~cm}^{-1}$ due to the distinctive dual peak pattern known to be sensitive to paracetamol polymorphism.[18,31] The resulting PCA model was used to confirm the crystal form of the recrystallized paracetamol samples.

Reference samples of amorphous and form II paracetamol for quantitative analysis were prepared by sandwiching a layer of molten paracetamol with a fixed height between a microscope slide and a cover slip. By combining and stacking samples, various levels of total crystallinity were achieved. The stacked samples were measured from opposite directions, and the spectra were averaged. The spectra were subjected to principal component analysis and PC1 was plotted against crystalline content. Linear correlation of PC1 value and crystallinity of the sample enabled direct use of PC1 in the determination of crystallinity of the sample in the different timepoints.

\subsubsection{X-ray}

The end state crystallinity of samples exposed to dry air, humid air and nitrogen in the highest and lowest temperatures was determined using $x$-ray powder diffractometry (XRPD). The measurements were conducted using an x-ray diffractometer (Empyrean; Panalytical, Almelo, Netherlands) with a fixed divergence slit of $0.19 \mathrm{~mm}$, general voltage of $45 \mathrm{kV}$ and tube current of $40 \mathrm{~mA}$. The step size was $0.01313^{\circ}$ and time per step was $99.195 \mathrm{~s}$. The measurement was performed over an angular range of 5 to $50^{\circ}$.

\subsubsection{Microscopy}

210 Optical microscopy (Nikon Optishot; Tokyo, Japan) was used in visual inspection of the samples prepared in $\mathrm{N}_{2}$ atmosphere and measured in a temperature of $20.5-21.4^{\circ} \mathrm{C}$.

\section{Results and discussion}

\subsection{Solid state analysis}

The solid state of the starting material, melted and cooled samples and end products were compared with data obtained of amorphous paracetamol and crystalline forms I and II (Fig. 3). The Raman spectrum of paracetamol has a distinctive double peak pattern in the Raman shift area of $1592-1634 \mathrm{~cm}^{-1} .[18,31]$ In form

$220 \mathrm{I}$, the peaks are clearly separate. Conversion to form II causes the first peak to shift towards higher wave numbers whereas the second peak shifts towards lower wave numbers, resulting in the peaks being more pronouncedly overlapping. The Raman spectrum of the starting material showed distinct features of form I, whereas the recrystallized samples showed clear indications of form II. The sample holder caused clearly detectable background noise and the peaks were overall less distinguishable than those typically reported in

225 the literature. Although the peaks are less intense, amorphous form and different polymorphs can be easily separated from each other. The amorphous samples showed mainly background caused by the sample holder.

The Raman spectroscopy findings were confirmed using differential scanning calorimetry. The onset $T_{g}$ of 230 the amorphous sample was $22.3 \pm 0.1^{\circ} \mathrm{C}$ and the sample started to recrystallize at $65.8 \pm 0.3^{\circ} \mathrm{C}$ and the melting point was detected at $157.8 \pm 0.2^{\circ} \mathrm{C}$ (Fig. 4). The melting point indicated that the amorphous sample had crystallized into form II, which corresponds to crystallization routes reported in previous studies using the same heating rate. ${ }^{22}$ XRPD results confirmed that at the end state, samples were crystallized to form II.

235 The recrystallized amorphous samples showed signs of glass transition at the expected temperature range and form II as indicated in Raman spectroscopy measurements (Fig. 4). In the thermogram, a melting peak is detected at $169.0^{\circ} \mathrm{C}$, which corresponds to that of form I $\left(168-172{ }^{\circ} \mathrm{C}\right)$ found in the literature.[22,32-34] No exothermic transitions indicating recrystallization prior to melting were detected in the thermogram. This is in line with findings by Kauffman et al. [31]. They used simultaneous Raman spectroscopy and DSC to measure aging of paracetamol form II. They discovered that paracetamol can convert from form II to form I 
without showing evidence of an exothermic event in the thermogram. Furthermore, Di Martino et al. [33] reported that paracetamol form II produces a similar thermogram to form I, even though the forms were distinctively separate using XRPD. The present study provides further evidence that DSC is not a suitable analytical method to alone confirm presence of paracetamol form II.

\subsection{Recrystallization of amorphous paracetamol}

The Raman spectra obtained during monitoring of recrystallization show that the initial amorphous state is maintained for hours (Fig. 5). When crystallization occurred, the sample recrystallized to a fairly stable end state crystal content level within minutes, with the distinctive pattern of paracetamol form II gradually emerging in the Raman spectra. To ensure the crystallization pathway, a PCA model was constructed. The model had two components which combined explained $94.3 \%$ of the variation. The $R^{2}$ and $Q^{2}$ values were 0.953 and 0.951 , respectively (Fig. 6). The first component $(83.4 \%)$ distinguished mainly crystalline paracetamol from amorphous, whereas the second component $(11.9 \%)$ separated paracetamol form I from form II, although this division between information content in the components was not explicitly categorical.

All samples crystallized from amorphous exclusively to form II, as expected based on literature findings.[18,31] The PCA model showed a distinct onset of crystallization, a rapid recrystallization and a clearly defined end state crystallinity. No signs of chemical degradation were seen in the Raman spectrum and no discoloration indicating thermal degradation was detected upon visual inspection of the samples. Furthermore, the gaseous atmospheres contained only marginal amounts of water. As no signs of oxidative or thermal degeneration were detected, and no evidence of water-induced plastization was seen in dry samples, one could be inclined to draw the conclusion that the observed phenomena were mainly governed by the physisorption of headspace gas molecules onto the amorphous surfaces. Andronis et al. [35] reported that limited amounts of humidity delayed the onset of crystallization and made the crystallization rate of amorphous indomethacin smaller. This phenomenon occurred, when the humidity was high enough to convert inclusive surface crystallization into bulk crystallization. However, in the present study, no sign of reduction of crystallization rate was seen when comparing crystallization of paracetamol samples in dry conditions at the lowest temperature.

270 To investigate crystallization kinetics, linear parts of the crystallization curve were fit in the Avrami equation $y=1-e^{\left(-k(t-\tau)^{n}\right)}$, in which $\mathrm{y}$ is the amount of crystalline substance, $k$ describes the rate of conversion, $t$ is time, $\tau$ is the lag time before onset of crystallization and $n$ describes the dimensionality of crystal growth.[36,37] In all dry samples Avrami constant $n$ was about 1 indicating that crystallization happened exclusively in the surface (Table I).

275 In almost all samples, the end state crystallinity was clearly below $100 \%$ (Table I). Only two of the samples reached over $80 \%$ crystallinity. The incomplete crystallization is expected and can be below the glass transition temperature be attributed to the rapid nature of surface crystallization in comparison to bulk crystallization $^{9}$, causes the crystallization rate to decrease significantly when surface crystallization is complete. In the super-cooled liquid state, amorphous paracetamol undergoes primary and secondary crystallization as described by Nikolakakis and Kachrimanis [38], with the secondary crystallization having a pronounced temperature dependency.

The sample was fairly thick, which renders the bulk of the sample overrepresented in comparison to the surface, when comparing sample thicknesses presented in a number of studies found in the literature [1114,39-45]. The rapid crystallization, low end state crystallization and visual inspection of the samples confirm that the crystallization was strongly surface-bound. The variation in end state crystallinity between similar samples could be attributed to the sample attaining various shapes upon melting and cooling, which would alter the surface/bulk-ratio of the samples and also affect the temperature gradients within the sample during melting, cooling and storage.

\subsection{Effect of headspace gas on the recrystallization of amorphous paracetamol}

Stringent temperature and humidity control was needed to ensure that temperature and humidity effects were excluded, and rigorously executed sample preparation routines were applied to enable repeatable sample history. Having cleared these prerequisites, the gaseous environment needed to be created and stabilized. As explained in section 2.1., all of these features were achieved, and consequently one could expect that the effects of headspace gas is reflected in the results. As the molecular events in nucleation are very subtle in volume and the events as such were expected to be below the detection limit of relevant 
analytical methods, direct evidence of interactions was not expected. Therefore, the crystal habit and recrystallization rate were used as indicators of events during the nucleation phase.

In the present study, there were clear differences in onset of crystallization based on the composition of the headspace gas and temperature (Fig. 7). When storing the amorphous paracetamol well below $T_{g}$, the onset of crystallization was clearly delayed in the presence of dry air when compared to nitrogen, whereas no distinct difference between these was noticed clearly above the onset of $T_{g}$. This is in line with earlier findings. Zografi and Newman [46] reported that below Tg, non-relaxed amorphous samples absorb more water than relaxed samples, whereas above Tg similar behavior was not observed. Similarly, one could expect that any other component in the gaseous phase with a tendency to interact with the amorphous surface should show the same behavior. In the present study, this was clearly seen when comparing nitrogen and dry air above and below Tg. This can be attributed to the composition of the gaseous phase, since the samples were treated in the same way in all other aspects.

As the interaction between gas and solid begins at the interphase, sorption is a relevant phenomenon to consider in the present study. The sorption of gases into amorphous solids can be divided into three separate steps: adsorption onto the surface, dissolution into the surface layer of the solid and diffusion into the matrix. The temperature of the system has a crucial role in all of these. Adsorption through physical interaction is known to be favored in low temperatures, which consequently means that as temperature increases, the amount of adsorption decreases correspondingly. The dissolution of gases is an exothermic process. In low temperatures, the solubility is thus higher than in high temperatures. As seen, the first two steps in sorption are both governed by temperature in the same way, i.e. in lower temperatures create the prerequisites for gas deposition from the gaseous phase into the solid phase. This partially explains the behavior observed in the present study as discussed below.

Henry's law postulates that the amount of dissolved gas in a liquid is dependent on the partial pressure of the headspace gas. An underlying assumption in Henry's law sorption is that there is no interaction between the solute and the solvent, rendering diffusion of the gas molecules in the matrix purely Fickian.[47] In this case the diffusion would be governed by concentration gradient, distance, viscosity of the matrix, temperature and size of the diffusing molecule. When considering this framework, some conclusions can be made. Mateucci et al. [48] described the impact of the kinetic diameter of $\mathrm{O}_{2}(3.46 \AA), \mathrm{N}_{2}(3.64 \AA)$ and $\mathrm{CO}_{2}$ $(3.3 \AA)$ on diffusion in polymer matrices. They describe that the diffusion coefficients of gases in amorphous polymers are highly dependent on both kinetic diameter of the penetrant gas and the free volume of the amorphous system. Based on the kinetic diameters of the gases, one would expect carbon dioxide to diffuse into the bulk of the sample more readily than oxygen or nitrogen. The data of the present study, shown in Figure 7, however, does not indicate that the size of the diffusing penetrant would have any effect on the recrystallization of amorphous paracetamol. The free volume in the amorphous matrix, however, is greater than that in a super-cooled liquid [49], which may enable molecular interactions with gas to occur more readily below the glass transition temperature. Evidence of this is seen in Figure 7, that clearly shows that below $T_{g}$ there are differences between effects of gases on amorphous paracetamol in the present study, whereas above $T_{g}$ no clear difference can be seen.

The viscosity of paracetamol melt at the melting point is around $10^{1}-10^{2} \mathrm{~Pa} \cdot \mathrm{s}$ [50] and as the temperature becomes lower the viscosity rapidly increases and reaches values of $10^{12}-10^{14} \mathrm{~Pa} \cdot \mathrm{s}$ in the glassy state [51]. As defined in the Stokes-Einstein equation, the diffusion coefficient is directly proportional to temperature and inversely proportional to the size of the gas molecule and the viscosity of the amorphous matrix. An increase in temperature would consequently have a dual effect on diffusion; the temperature increase itself would cause increased molecular motion and the increase in temperature would reduce viscosity, further promoting molecular mobility and consequently diffusion of gas from the surface to the bulk. In lower temperatures the opposite would hold, resulting in reduced diffusion from the surface to the bulk and consequently enabling a build-up of gas molecules on the surface of the glassy substance. This, combined with the fact that recrystallization of amorphous substances is highly surface-driven and the rigidity of the surface is a prerequisite for superior surface crystallization rate compared that of the bulk [9], further emphasizes that temperature is of key importance in the interactions at the solid/gas-interface of amorphous systems. This also supports the findings shown in Figure 7.

355 When studying the temperature dependence of recrystallization of amorphous paracetamol, it is evident that the onset of recrystallization in the presence of humid air, $\mathrm{N}_{2}$ and $\mathrm{CO}_{2}$ is not temperature dependent, whereas the onset of crystallization is delayed in lower temperatures in the presence of dry air (Fig. 7 and Fig. 8). The effect of moisture on crystallization of amorphous samples is commonly known to be significant. 
When comparing the difference between dry air, humid air and $\mathrm{N}_{2}$ on the onset of crystallization below the glass transition temperature, one can see that the difference in onset of crystallization between dry air and $\mathrm{N}_{2}$ is comparable to that between dry air and humid air, which is commonly known to be of significant magnitude. This pronounces the importance of this study in showing that the effect of gaseous environment in crystallization is larger than previously known, and that the phenomenon itself deserves more attention in the scientific community.

Taken together, the temperature dependency of onset of crystallization in the present study could be explained by the exothermic nature of adsorption and by the fact that as the temperature is lower, the solubility of gases into the amorphous matrix is lower. Furthermore, the viscosity of the amorphous glass is higher and as a consequence the surface is more rigid, which has been found to promote surface crystallization.[9] As the temperature exceeds the glass transition temperature, the sample becomes a super-cooled liquid, whereby surface crystallization is no longer dominant over bulk crystallization. This explains the fact that no difference in onset of crystallization was detected between headspace gases above the onset of glass transition temperature. In the temperatures of $17.2 \pm 0.3^{\circ} \mathrm{C}, 21.7 \pm 0.2^{\circ} \mathrm{C}$ and $23.9 \pm 0.4^{\circ} \mathrm{C}$, crystallization followed a typical sigmoidal curve. On the other hand, in the highest temperatures of $27.5 \pm 0.2$ ${ }^{\circ} \mathrm{C}$ and with dry atmospheres, crystallization occurred stepwise with sigmoidal steps followed by intermittent lag times. In the highest temperature, there was also great variation between samples. Instable crystallization kinetics of amorphous material above $\mathrm{T}_{\mathrm{g}}$ has been supported by $\mathrm{Yu}$ [9]. The temperature dependence is clearly shown in Figure 7 and Figure 8, especially regarding crystallization in presence of dry air, and consequently the observed behaviour can be regarded as logical and expected.

The rapid nature of crystallization of paracetamol in humid air as compared to dry air in the present study in, with a greater difference below glass transition than above, is an expected outcome. As commonly known, amorphous substances are hygroscopic, and water absorption plasticizes amorphous substances, which results in lower glass transition temperature and thus higher molecular mobility in isothermal conditions.[15] The crystallization rate of amorphous paracetamol has been shown to increase as relative humidity increases.[54,55] It has been reported that adsorbed water has an antiplasticizing effect at low levels of water uptake, which would postpone the onset of crystallization.[46] Furthermore, Novakovic et al. [56] found evidence of high-energy regions undergoing more extensive relaxation in elevated humidity compared to lower humidity, which resulted in less pronounced crystallization. However, the differences in onset of crystallization between dry air and $\mathrm{N}_{2}$ cannot be explained by differences in moisture content, when you consider the amount of water in the gas and the theoretical amount of collisions onto the sample surface (Table II). Furthermore, the moisture content in the carbon dioxide atmosphere lies between that of nitrogen and dry air, which is not reflected in onset of crystallization. This, in combination with the Avrami constant, indicates that the explanation to the difference in onset of crystallization between air and nitrogen cannot be explained by water interactions.

It has previously been shown that gases may interact with hydrogen bond forming groups of amorphous substances $[20,23,57]$, whereby the assumption of purely Fickian penetrant gas diffusion would become invalid. If there was any attractive interaction between the gas and the molecules in the glassy or supercooled substance, the diffusive transfer of gas molecules into the bulk could be delayed or disabled, leading to an accumulation of gas on and near the surface of the sample. In amorphous substances below $\mathrm{T}_{\mathrm{g}}$, the motion on the surface is considerably higher than that of the bulk, and it has been shown that recrystallization of amorphous substances is highly surface-driven.[9] Gunawan et al. [58] showed that there are hydrogen bonds between the amine group and phenolic hydroxyl and between the carbonyl oxygen and phenolic hydroxyl in the liquid and glassy state, and Tombari et al. [59] discuss that the molecules in glassy or liquid paracetamol are in motion due to constantly breaking and reforming hydrogen bonds between amine and hydroxyl groups of the paracetamol molecules. Furthermore, Gunawan et al. [58] showed that hydrogen bonding has an effect on the structural relaxation of the glass. Klopffer and Flaconnèche [47] showed with polymers, that as adsorbed gas molecules interact with the hydrogen bond forming groups in the amorphous matrix, the structural characteristics and state of motion of the molecules are disturbed. Trasi and Taylor [60] found that the bond between the phenolic hydroxyl and the carbonyl oxygen is stronger than the bond between the amine group and the phenolic hydroxyl. They studied hydrogen bonding in pure paracetamol and blends of polymers and paracetamol using FTIR, and found that introducing stronger hydrogen bond donors and acceptors to the system interfered with the hydrogen bonding network between paracetamol molecules, which reduced the amount of nuclei formed. Combined, these studies strongly suggest that amorphous paracetamol can interact with the gaseous environment and the interactions would have an effect on crystallization; the present study brings experimental observations that support this hypothesis. 
420 In crystalline substances, it has been shown that different faces of the crystal interact with gases depending on which functional groups are exposed at the interface.[23] The interactions between amorphous solid surfaces and the gaseous phase is more complex than with crystalline substances, since the surface of amorphous solids is a dynamic interface that experiences variation in the form of random orientation of mobile molecules, constant migration towards more ordered states over time and changes over time in the 425 form of relaxation. The molecules in the surface layer of amorphous paracetamol are randomly ordered, which presents various functional groups to the gaseous phase. Since physisorption can occur site specifically, one could assume that amine, phenolic hydroxyl and carbonyl oxygen of paracetamol with a tendency to hydrogen bonding, could interact with gaseous $\mathrm{N}_{2}$ and especially $\mathrm{O}_{2}$. The adsorption of gas molecules on the surface layer could interfere with the formation of nuclei of paracetamol form II, consequently delaying the onset of crystallization. As $\mathrm{O}_{2}$ has a more pronounced electronegativity than $\mathrm{N}_{2}$, one could expect that a headspace atmosphere containing $\mathrm{O}_{2}$ would more strongly interact with the hydrogen bonding sites of amorphous paracetamol and thus interfering with the hydrogen bonding network (Fig. 9) and formation of paracetamol form II nuclei. This hypothesis is supported by Manca et al. [58], who studied the interaction between gases and amorphous ice. They found that $\mathrm{N}_{2}$ and $\mathrm{CO}_{2}$ underwent site specific adsorption by hydrogen bonding with exposed hydroxyl groups on the surface of the amorphous substance. It cannot be excluded that similar site specific bonding can take place in amorphous paracetamol based on the results of the present study (Figure 7.), but obtaining direct evidence is highly challenging due to detection limit restrictions.

440 Paracetamol is a compound known to readily form a glass when cooling the melt, but which recrystallizes rapidly upon heating.[60] The nucleation and growth temperature zones of paracetamol are also well separated, with a nucleation zone of 50-60 ${ }^{\circ} \mathrm{C}$.[60] As all samples were cooled through the nucleation temperature zone and below the glass transition temperature in the present study, and kept below the crystal growth temperature zone, the effects of gas exposure are isolated on nucleation in the present study. As $\mathrm{O}_{2}$

445 has a stronger tendency towards hydrogen bonding than $\mathrm{N}_{2}$, the decrease in crystallization onset in the present study may be caused by $\mathrm{O}_{2}$ forming hydrogen bonds on the sample surface, which decreases the amount of nuclei forming in the glass. As the temperature exceeds the glass transition temperature, bulk crystallization gains importance while gas adsorption becomes less pronounced, rendering the effect of gas exposure on the nucleation rate less prominent. Furthermore, effects on the structural relaxations of the amorphous glass cannot be excluded. No difference in crystallization rate was observed once the onset was detected (Table I), and all samples crystallized into form II as detected with DSC, Raman and XRPD, which further supports the gas having a primary effect on nucleation.

The samples in the present study showed some variation in onset of crystallization within groups. In the amorphous samples that have been cooled from super-cooled liquid, one can find spatial and dynamic heterogeneity.[62,63] In other words, there are local regions of molecules relaxing at varying rate, which in the present study can be seen in the clear differences between onset times of crystallization within temperature and atmosphere categories (Table I). Kinetically these differences can be represented with potential energy mapping, which show distinct potential energy differences between different small areas in 460 the sample.[64] Since the samples in the present study were not treated in a way that would cause nuclei to form, spatial and dynamic heterogeneity could have a significant impact on the length of the lag-time before onset of recrystallization since stable nuclei have to be formed before the crystallization can happen. Heterogeneous nucleation may occur, when foreign surfaces interacts with the amorphous material.[65,66] In the present study, the onset of crystallization occurred at the edge of the sample where the super-cooled liquid phase, solid glass phase and gaseous phase met (Fig. 10a). From the edge of the sample the crystallization progressed along the sample surface towards the centre of the sample (Fig. 10b). Surface curvature, pronounced molecular mobility on the surface and contact with the foreign glass surface could in combination generate high energy sites at the contact point between the phases, which could facilitate the onset of crystallization. A broad standard deviation in crystallization onset is thus an expected finding, and a fact that brings further challenge into this complicated experimental setup.

To summarize, it is known that physisorption is facilitated in low temperatures and may occur through hydrogen bonding in active sites. The adsorption and dissolution of gases into the matrix increase whereas viscosity of amorphous samples becomes higher with decreasing temperature. Combined with the tendency towards surface crystallization, it can be concluded that the headspace gas affects the onset of recrystallization of paracetamol below $T_{g}$. In temperatures above $T_{g}$ the opposite occurs and the differences caused by variation in headspace gas are canceled. In addition, in temperatures above $T_{g}$ bulk crystallization gains significance while surface crystallization becomes less prominent. 


\section{Conclusions}

The headspace gas seems to have a more significant role in the stability of amorphous pharmaceuticals than previously reported. The present study showed that in amorphous paracetamol samples, exposure to dry air delayed the onset of crystallization in comparison to samples exposed to pure nitrogen when the temperature was kept below $T_{g}$. Above $T_{g}$ no difference between dry air and nitrogen was detected. The results imply that oxygen, being a reactive gas, was adsorbed onto the surface of the amorphous glass where it interfered with the hydrogen bonding between paracetamol molecules. This may have prevented nucleation and subsequently delayed the onset of crystallization. Nitrogen, being an inert gas, does not interact with the sample surface, and consequently the nucleation and onset of crystallization occurred without molecular interaction between the gaseous and solid phases, leaving the sample to behave according to its inherent physical instability. Since atmospheric gases may have an effect on the physical stability of amorphous pharmaceutics, more studies are needed in this area to fully clarify the nature of interaction between the headspace gas and amorphous pharmaceuticals. The present study confirms that this previously neglected topic deserves further attention in the scientific community.

\section{Acknowledgements}

Academy of Finland (Suomen Akatemia), Orion Research Foundation sr and the Vilho, Yrjö and Kalle Väisälä Foundation are acknowledged for financial support of the study. Doctor Heikki Räikkönen is 500 acknowledge for help with XRPD measurements. Professor Clare Strachan is acknowledged for great discussions about the content of the article.

\section{Declaration of interest}

505 None.

\section{References}

1. Cooper ER. Nanoparticles: A personal experience for formulating poorly water soluble drugs. J Control 510 Release 2010;141:300-302.

2. Lipinski C. Poor Aqueous Solubility - an Industry Wide Problem in Drug Discovery. Am Pharm Rev 2002;5(3):82-85.

515 3. Hancock BC, Zografi G. Characteristics and significance of the amorphous state in pharmaceutical systems. J Pharm Sci 1997;86(1):1-12.

4. Yu L. Amorphous pharmaceutical solids: preparation: characterization and stabilization. Adv Drug Deliv Rev 2001;28:27-42.

5. Bhugra C, Pikal MJ. Role of thermodynamic, molecular and kinetic factors in crystallization from the amorphous state. J Pharm Sci 2008;97(4):1329-1349.

6. Laitinen R, Löbmann K, Strachan CJ, Grohganz H, Rades T. Emerging trends in the stabilization of 525 amorphous drugs. Int J Pharm 2013;453:65-79.

7. Baird JA, Van Eerdenbrugh B, Taylor LS. A Classification System to Assess the Crystallization Tendency of Organic Molecules from Undercooled Melts. J Pharm Sci 2010;99(9):3787-3806.

530 8. Mahlin D, Bengström CAS. Early drug development predictions of glass-forming ability and physical stability of drugs. Eur J Pharm Sci 2013;49:323-332.

9. Yu L. Surface mobility of molecular glasses and its importance in physical stability. Adv Drug Deliv Rev 2016;100:3-9.

10. Zhu L, Jona J, Nagapudi K, Wu T. Fast surface crystallization of amorphous griseofulvin below $T_{g}$. Pharm Res 2010;27:1558-1567. 
11. Zhu L, Wong L, Yu L. Surface-Enhanced crystallization of amorphous nifedipine. Mol Pharm 2008;5(6):921-926.

12. Wu T, Yu L. Surface crystallization of indomethacin below $T_{g}$. Pharm Res 2006;23(10):2350-2355.

13. $\mathrm{Wu} T$, Sun $\mathrm{Y}$, de Villiers MM, Yu L. Inhibiting surface crystallization of amorphous indomethacin by nanocoating. Langmuir 2007;23:5148-5153.

14. Kestur US, Taylor LS. Evaluation of the Crystal Growth Rate of Felodipine Polymorphs in the Presence and Absence of Additives As a Function of Temperature. Cryst Growth Des 2013;13:4349-4354.

550 15. Hancock B, Zografi G. The relationship between glass transition temperature and the water content of amorphous pharmaceutical solids. Pharm Res 1994;11(4):471-477.

16. Qi S, Avalle P, Saklatvala R, Craig DQM. An investigation into the effects of thermal history on the crystallisation behaviour of amorphous paracetamol. Eur J Pharm Biopharm 2008;69:364-371.

17. Perrin M-A, Neumann MA, Elmaleh H, Zarke L. Crystal structure determination of the elusive paracetamol Form III, Chemical Communications 2009;22:3181-3183.

18. Nanubolu BJ, Burley JC. Investigating the Recrystallization Behavior of Amorphous Paracetamol by Variable Temperature Raman Studies and Surface Raman Mapping. Mol Pharmaceutics 2012;9:1544-1558.

19. Sibik J, Sargent MJ, Franklin M, Zeitler JA. Crystallization and Phase Changes in Paracetamol from the Amorphous Solid to the Liquid Phase. Mol Pharmaceutics 2014;11:1326-1334.

565 20. Byrn SR, Xu W, Newman AW. Chemical reactivity in solid-state pharmaceuticals: formulation implications. Adv Drug Deliv Rev 2001;48:115-136.

21. Chen X, Morris KR, Griesser UJ, Byrn SR, Stowell JG. Reactivity Differences of Indomethacin Solid Forms with Ammonia Gas. J Am Chem Soc 2002;124:15012-15019.

22. Di Martino P, Palmieri GF, Martelli S. Molecular Mobility of the Paracetamol Amorphous Form. Chem Pharm But 2000;48(8):1105-1108.

23. Buckton G, Gill H. The importance of surface energetics of powders for drug delivery and the establishment of inverse gas chromatography. Adv Drug Deliv Rev 2007;59:1474-1479.

24. Martínez LM, Videa M, López-Silva GA, de los Reyes CA, Cruz-Angeles J, González N. Stabilization of amorphous paracetamol based systems using traditional and novel strategies. Int J Pharm 2014;477;294305.

25. Gilpin RK, Zhou W. Studies of the Thermal Degradation of Acetaminophen Using a Conventional HPLC Approach and Electrospray Ionization-Mass Spectrometry. J Chromatogr Sci 2004;42,15-20.

26. Palomäki E, Ahvenainen $\mathrm{P}$, Ehlers $\mathrm{H}$, Svedström K, Huotari S, Yliruusi J. Monitoring the recrystallisation of amorphous xylitol using Raman spectroscopy and wide-angle X-ray scattering. Int J Pharm 2016;508:7182.

27. Johansson J, Pettersson S, Folestad S. Characterization of different laser irradiation methods for quantitative Raman tablet assessment. J Pharm Biomed 2005;39:510-516.

28. Paudel A, Raijada D, Rantanen J. Raman spectroscopy in pharmaceutical product design. Adv Drug Deliv Rev 2015;89:3-20.

29. Chieng N, Rades T, Aaltonen J. An overview of recent studies on the analysis of pharmaceutical polymorphs. J Pharm Biomed Anal 2011;55(4):618-644.

30. Strachan CJ, Rades T, Gorden K, Rantanen J. Raman spectroscopy for quantitative analysis of pharmaceutical solids. J Pharm Pharmacol 2007;59:179-192. 
31. Kauffman JF, Batykefer LM, Tuschel DD. Raman detected differential scanning calorimetry of polymorphic transformations in acetaminophen. J Pharmaceut Biomed 2008;48:1310-1315.

32. Di Martino P, Conflant P, Drache M, Huvenne J-P, Guyot-Hermann A-M. Preparation and physical characterization of form II and III paracetamol. J Therm Anal 1997;48:447-458.

33. Di Martino P, Guyot-Hermann A-M; Conflant P, Drache M, Guyot J-C. A new pure paracetamol for direct compression: the orthorhombic form. Int J Pharm 1996;128:1-8.

34. Nichols G, Frampton CS. Physicochemical Characterization of the Orthorhombic Polymorph of Paracetamol Crystallized from Solution. J Pharm Sci 1998;87(6):684-693.

35. Andronis V, Yoshioka M, Zografi G. Effects of Sorbed Water on the Crystallization of Indomethacin from the Amorphous State. J Pharm Sci 1997;86(3):346-351.

615 36. Tripathi $\mathrm{P}$, Romanini, M, Tamarit JL, Macovez, R. Collective relaxation dynamics and crystallization kinetics of the amorphous Biclotymol antiseptic. Int. J. Pharm. 2015;495(1),420-427.

37. Çelikbilek M, Ersundu AE, Aydın S. Crystallization kinetics of amorphous materials. In: Yitzhak Mastai (Ed.), Advances in Crystallization Processes. 2012;pp.127-162.

38. Nikolakakis I, Kachrimanis K. Crystallization kinetics of orthorhombic paracetamol from supercooled melts studied by non-isothermal DSC. Drug Dev Ind Pharm 2016;43(2):257-263.

39. Daley CR, Fakhraai Z, Ediger MD, Forrest JA. Comparing surface and bulk flow of a molecular glass former. Soft Matter 2012;8:2206-2212.

40. Van Eerdenbrygh B, Braid JA, Taylor LS. Crystallization Tendency of Active Pharmaceutical Ingredients Following Rapid Solvent Evaporation-Classification and Comparison with Crystallization Tendency from Undercooled Melts. J Pharm Sci 2010;99(9): 3826-3838.

41. Ferreira NG, Abramof E, Corat EJ, Trava-Airoldi VJ. Residual stresses and crystalline quality of heavily boron-doped diamond films analysed by micro-Raman spectroscopy and X-ray diffraction. Carbon 2003;41:1301-1308.

635 42. Sibik J, Löbmann K, Rades T, Zeitler JA. Predicting Crystallization of Amorphous Drugs with Terahertz Spectroscopy. Mol. Pharmaceutics 2015;12:3062-3068.

43. Yang Z, Fujii Y. F.K. Lee, Lam C-H, Tsui OKC. Glass Transition Dynamics and Surface Layer Mobility in Unentangled Polystyrene Films. Science 2010;328:1676-1679.

44. Zhang W, Brian CW, Yu L. Fast Surface Diffusion of Amorphous o $\square$ Terphenyl and Its Competition with Viscous Flow in Surface Evolution. J Phys Chem B 2015;119:5071-5078.

45. Zhang L, Yu L. Surface Diffusion of Polymer Glasses. Macromolecules 2016;49:731-735.

46 Zografi G, Newman A. Interrelationships Between Structure and the Properties of Amorphous Solids of Pharmaceutical Interest. J Pharm Sci 2017;106;5-27.

47. Klopffer MH, Flaconnèche B. Transport properties of gases in polymers: Bibliographic review. Oil \& Gas 650 Sci Technol 2001;56(3):223-244.

48. Mateucci S, Yampolskii Y, Freeman BC, Pinnau, I. Transport of Gases and Vapors in Glassy and Rubbery Polymers. In: Yampolskii Y, Pinnau I, Freeman B, eds. Materials Science of Membranes for Gas and Vapor Separation. Chichester, England: John Wiley \& Sons; 2006:1-48.

49. Hilden LR, Morris KR. Physics of Amorphous Solids. J Pharm Sci 2004;93(1):3-12. 
50. Baird JA, Santiogo-Quinonez D, Rinaldi C, Taylor LS. Role of viscosity in influencing the glass-forming ability of organic molecules from the undercooled melt state. Pharm Res 2012;29:271-284.

660

665

51. Craig DQM, Royall PG, Kett VL, Hopton ML. The relevance of the amorphous state to pharmaceutical dosage forms: glassy drugs and freeze dried systems. Int J Pharm 1999;179:179-207.

52. Atkins PW. Physical Pharmacy, sixth ed., Oxford University Press, Oxford 1998;pp.835.

53. Jensen F. Introduction to Computational Chemistry, third ed., John Wiley \& sons, Ltd, Aarhus 2017;pp.450.

54. Lehmkemper K, Kyeremateng SO, Heinzerling O, Degenhardt M, Sadowski G. Impact of Polymer Type and Relative Humidity on the Long-Term Physical Stability of Amorphous Solid Dispersions. Mol. Pharmaceutics. 2017;14:4374-4386.

55. Hoppu P, Jouppila K, Rantanen J, Schantz S, Juppo AM. Characterization of blends of paracetamol and cityric acid. Int J Pharm Pharmacol 2007;59:373-381.

56. Novakovic D, Isomäki A, Pleunis B, Fraser-Miller SJ, Peltonen L, Laaksonen T, Strachan CJ. Understanding Dissolution and Crystallization with Imaging: A Surface Point of View. Mol Pharmaceut 2018;15;5361-5373

680 57. Manca C, Martin C, Roubin P. Comparative Study of Gas Adsorption on amorphous Ice: Thermodynamic and Spectroscopic Features of the Adlayer on the Surface. J Phys Chem B 2003;107:8929-8934.

58. Gunawan L, Johari GP, Shanker RM. Structural relaxation of acetaminophen glass. Pharm Res 2006;23(5):967-979.

59. Tombari E, Presto S, Shanker RM, Johari GP. Crystallization kinetics of ultraviscous acetaminophen by heat capacity and enthalpy measurements and diffucion control. J Phys Chem B 2009;113:15293-15303.

60. Trasi NJ, Taylor LS. Effect pf polymers on nucleation and crystal growth of amorphous acetaminophen. CrystEngComm 2012;14:5188-5197.

61. Oswald IDH, Allan DR, McGregor PA, Motherwell WS, Parsons S, Pulham CR. The formation of paracetamol (acetaminophen) adducts with hydrogen-bond acceptors. Acta Crystall B-Stru 2002;58(6):1057-1066.

62. Ediger MD. Spatially heterogeneous dynamics in supercooled liquids. Annu Rev Phys Chem 2000;51:99-128.

63. Sillescu H. Heterogeneity at the glass transition: A review. J Non-Cryst Solids 1999;243:81-108.

64. Cui Y. A material science perspective of pharmaceutical solids. Int J Pharm 2007;339:3-18.

65. Hellrup J, Mahlin D. Pharmaceutical micro-particles give amorphous sucrose higher physical stability. Int J Pharm 2011;409:96-103.

66. Bhatt V, Shete G, Bansal AK. Mechanism of generation of drug nanocrystals in celecoxib: mannitol nanocrystalline solid dispersion. Int J Pharm 2015;495:132-139. 


\section{ACCEPTED MANUSCRIPT}

Figure 1. Schematic representation of the sample holder. The sample holder enables maintaining an isolated gaseous atmosphere during storage. The Raman measurements were performed through the glass bottom of the sample holder.

Figure 2. Flow diagram of the processing and solid-state analysis of amorphous paracetamol.

715 Figure 3. Typical Raman spectra of a) Form I, b) amorphous and c) Form II paracetamol obtained in the present study.

Figure 4. Typical DSC thermograms of a) form I reference sample (dark grey, dashed), b) amorphous paracetamol (black) and c) crystallized form II sample (light grey).

Figure 5. Typical Raman spectra of amoprhous paracetamol recrystallizing in the presence of dry air $\left(\mathrm{T}=21.8-21.9^{\circ} \mathrm{C}\right)$ without pretreatments.

Figure 6. PCA models of crystallization of representative samples of amorphous paracetamol at temperature of $21.7 \pm 0.2{ }^{\circ} \mathrm{C}$ in a) dry air atmosphere, b) dry carbon dioxide atmosphere, c) dry nitrogen atmosphere and d) humid air atmosphere. Recrystallizing samples are shown with small black circles, amorphous reference samples with red unfilled circles, form I reference samples with red unfilled triangles and form II reference samples with red unfilled squares. Data points are shown with 1-minute intervals from 0 to 1200 minutes to alleviate interpretation.

Figure 7. Average onset of crystallization of paracetamol in different temperatures and headspace atmospheres.

Figure 8. Average onset of crystallization of paracetamol in dry air atmosphere.

Figure 9. Hydrogen bonding network of paracetamol form II. [61]

Figure 10. Microscope image of the progress of recrystallization of amorphous paracetamol.

740 Table I. Crystallization of paracetamol in different temperatures and atmospheres.

Table II. Amount of water in various gas mixtures and collision number of water molecules. Calculations assume temperature of $20^{\circ} \mathrm{C}$ and normal atmospheric pressure. 
Table I. Crystallization of paracetamol in different temperatures and atmospheres.

\begin{tabular}{|c|c|c|c|c|c|}
\hline $\begin{array}{c}\text { Temperature } \\
\left({ }^{\circ} \mathrm{C}\right)\end{array}$ & Atmosphere & $\begin{array}{l}\text { On set of } \\
\text { crystallization } \\
\text { (min) }\end{array}$ & $\begin{array}{l}\text { Crystallization } \\
\text { time (min) }\end{array}$ & $\begin{array}{l}\text { End state } \\
\text { crystallinity } \\
(\%)\end{array}$ & $\begin{array}{c}\text { Avrami } \\
\text { constant } n\end{array}$ \\
\hline $17.1-17.3$ & Air & 1457.0 & 50.5 & 41.9 & 0.95 \\
\hline $16.9-17.1$ & Air & 1502.5 & 94.0 & 59.3 & 1.00 \\
\hline $17.0-17.2$ & Air & 1161.5 & 75.0 & 64.9 & 1.06 \\
\hline $17.0-17.2$ & Carbon dioxide & 238.0 & 50.5 & 31.6 & 0.98 \\
\hline $17.0-17.2$ & Carbon dioxide & 707.0 & 29.0 & 46.3 & 1.17 \\
\hline $17.0-17.2$ & Carbon dioxide & 807.5 & 75.5 & 53.4 & 0.97 \\
\hline $17.1-17.4$ & Nitrogen & 294.0 & 25.0 & 28.9 & 0.67 \\
\hline $17.1-17.4$ & Nitrogen & 574.5 & 74.0 & 42.5 & 0.83 \\
\hline $17.1-17.4$ & Nitrogen & 664.0 & 78.0 & 19.9 & 0.54 \\
\hline 17.3-17.4 & Humid air & 220.5 & 134.5 & 34.3 & 1.01 \\
\hline $17.3-17.4$ & Humid air & 213.0 & 66.0 & 39.6 & 1.45 \\
\hline $17.0-17.2$ & Humid air & 87.5 & 157.0 & 37.1 & 1.43 \\
\hline 21.9 & Air & 1210.0 & 27.0 & 82.2 & 1.71 \\
\hline $21.8-21-9$ & Air & 801.0 & 35.0 & 85.8 & 1.74 \\
\hline $21.8-21-9$ & Air & 1000.0 & 21.5 & 22.0 & 2.08 \\
\hline $21.8-21-9$ & Carbon dioxide & 1158.5 & 49.0 & 42.6 & 1.15 \\
\hline $21.8-21-9$ & Carbon dioxide & 639.5 & 21.0 & 62.2 & 0.90 \\
\hline $21.7-21.8$ & Carbon dioxide & 675.5 & 17.0 & 51.9 & 0.87 \\
\hline $21.5-21.7$ & Nitrogen & 298.0 & 39.5 & 50.0 & 0.65 \\
\hline $21.7-21.8$ & Nitrogen & 521.0 & 40.5 & 28.7 & 0.84 \\
\hline $21.7-21.8$ & Nitrogen & 765.5 & 98.0 & 70.6 & 1.55 \\
\hline $21.6-21.8$ & Humid air & 284.0 & 132.0 & 50.6 & 2.18 \\
\hline $21.5-21.8$ & Humid air & 198. & 108.0 & 33.5 & 1.21 \\
\hline $21.5-21.7$ & Humid air & 203.5 & 98.0 & 34.6 & 1.35 \\
\hline $23.7-23.9$ & Air & 954.0 & 76.5 & 58.4 & 1.48 \\
\hline $23.5-24.1$ & Air & 781.5 & 53.0 & 68.1 & 1.07 \\
\hline $23.7-24.1$ & Air & 759.0 & 41.0 & 61.7 & 0.89 \\
\hline $23.6-24.2$ & Carbon dioxide & 518.0 & 58.0 & 60.0 & 0.91 \\
\hline $23.7-24.0$ & Carbon dioxide & 598.5 & 19.0 & 37.2 & 1.17 \\
\hline 23.6-23.9 & Carbon dioxide & 435.0 & 12.5 & 50.4 & 0.91 \\
\hline $23.8-24.0$ & Nitrogen & 445.5 & 38.5 & 39.8 & 1.30 \\
\hline $23.6-24.3$ & Nitrogen & 445.5 & 33.5 & 51.4 & 0.85 \\
\hline $23.6-24.2$ & Nitrogen & 278.5 & 98.0 & 71.6 & 1.96 \\
\hline $24.1-24.2$ & Humid air & 332.5 & 89.0 & 34.4 & 0.97 \\
\hline $24.0-243$ & Humid air & 77.0 & 87.0 & 18.4 & 1.13 \\
\hline $23.8-24.0$ & Humid air & 219.5 & 98.0 & 36.3 & 0.99 \\
\hline 27.3-27.4 & Air $^{*}$ & 161.5 & 64.5 & 29.5 & 1.15 \\
\hline $27.5-27.7$ & Air & 630.0 & 20.0 & 50.0 & 1.08 \\
\hline 27.3-27.5 & Air* & 294.0 & 163.5 & 29.5 & 1.62 \\
\hline $27.5-27.7$ & Carbon dioxide* & 448.0 & 668.5 & 44.3 & 0.88 \\
\hline 27.4-27.5 & Carbon dioxide* & 554.5 & 290.0 & 61.7 & $1.02 / 1.37$ \\
\hline 27.3-27.6 & Carbon dioxide* & 762.5 & 408.0 & 55.9 & $0.93 / 1.18$ \\
\hline $27.4-27.6$ & Nitrogen* & 191.0 & 169.0 & 26.9 & 0.78 \\
\hline 27.4-27.7 & Nitrogen* & 318.0 & 172.5 & 16.7 & 1.21 \\
\hline $27.4-27.6$ & Nitrogen* & 385.0 & 295.5 & 33.2 & 1.33 \\
\hline $27.3-27.6$ & Humid air & 225.0 & 193.0 & 41.6 & 1.15 \\
\hline $27.5-27.7$ & Humid air & 138.0 & 104.5 & 36.9 & 1.49 \\
\hline 27.4-27.7 & Humid air & 68.5 & 327.5 & 34.1 & 1.33 \\
\hline
\end{tabular}

${ }^{*}$ non-sigmoidal crystallization profile (crystallization slows down and becomes faster multiple times) 


\section{ACCEPTED MANUSCRIPT}

Table II. Amount of water in various gas mixtures and collision number of water molecules. Calculations assume temperature of $20^{\circ} \mathrm{C}$ and normal atmospheric pressure.

Atmosphere

$\mathrm{RH} \%$

$\mathrm{H}_{2} \mathrm{O}\left(\mathrm{g} / \mathrm{m}^{3}\right)$
$\mathrm{H}_{2} \mathrm{O}(\mathrm{m} / \mathrm{m}-\%)$ in the atmosphere

\section{Air}

$\mathrm{CO}_{2}$

$\mathrm{N}_{2}$

$$
\text { 4.4-4.7 }
$$

$1.2-1.5$

$\leq 0.1$

21.2-22.2
$0.21-0.26$
$\leq 0.2$

0.76-0.81

Humid air

3.67-3.85

${ }^{*}$ collision frequency $[52,53]$
Theoretical amount of collisions between gaseous $\mathrm{H} 2 \mathrm{O}$ molecules and the sample surface $\left(\mathrm{n} / \AA^{2} / \mathbf{s}\right)^{*}$

$$
\begin{gathered}
4200-4400 \\
1100-1400 \\
\leq 100
\end{gathered}
$$

20000-21000 

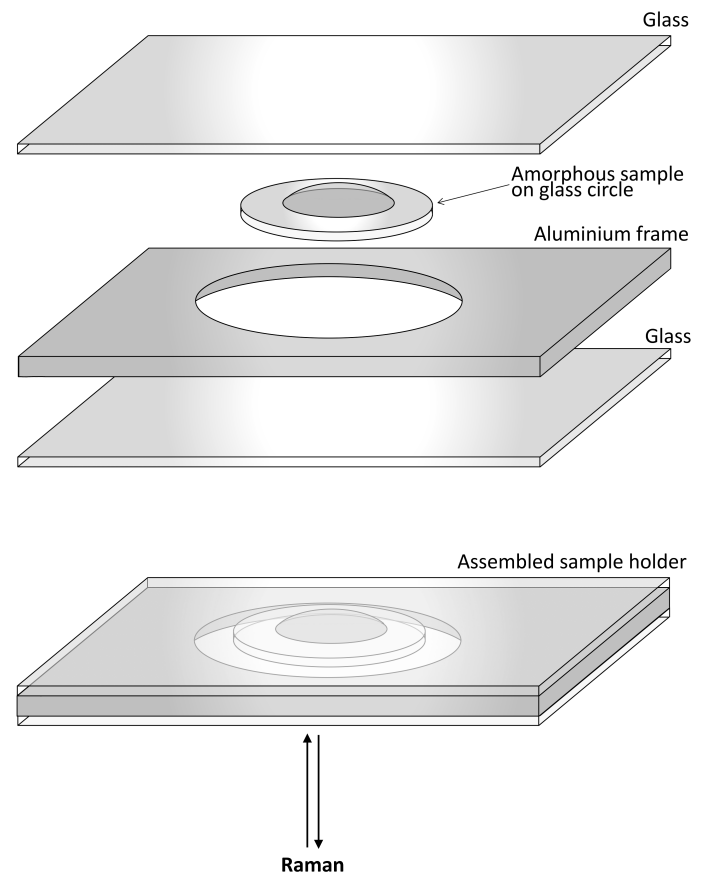

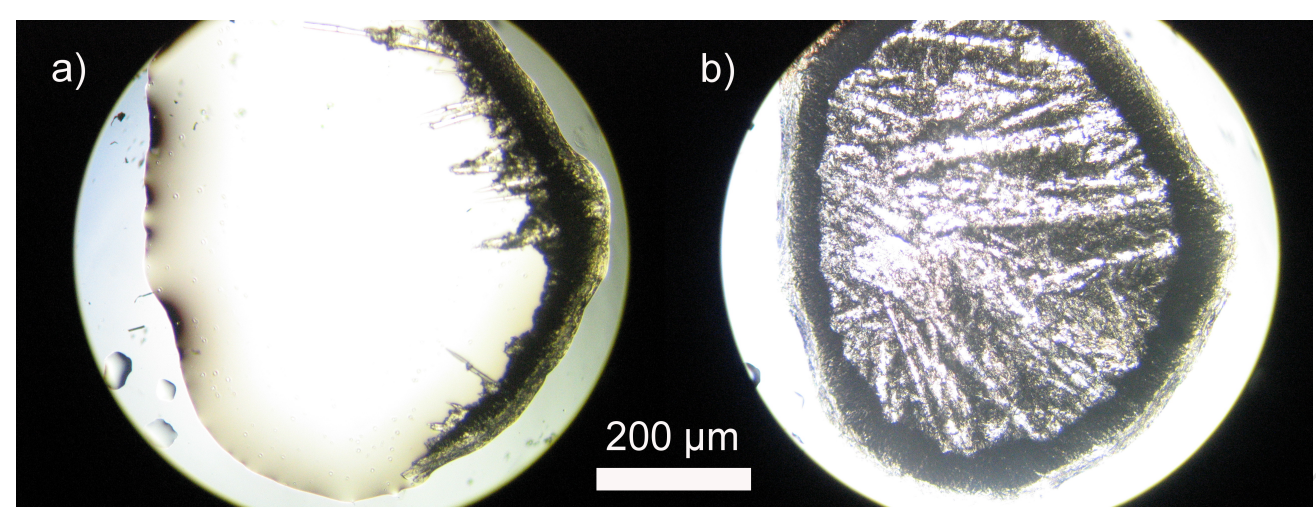


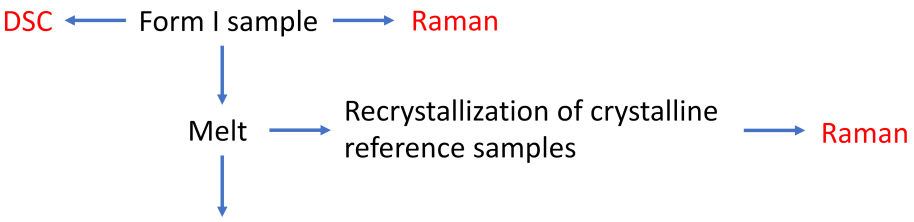

DSC of amorphous sample $\longleftarrow \begin{aligned} & \text { Cooled melt in } \\ & \text { sample holder }\end{aligned} \longrightarrow$ Amorphous reference sample $\longrightarrow$ Raman

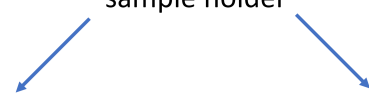

Microscopic evaluation of crystallization

Raman spectra of crystallization

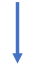

Crystallized sample

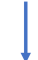

DSC of end product 


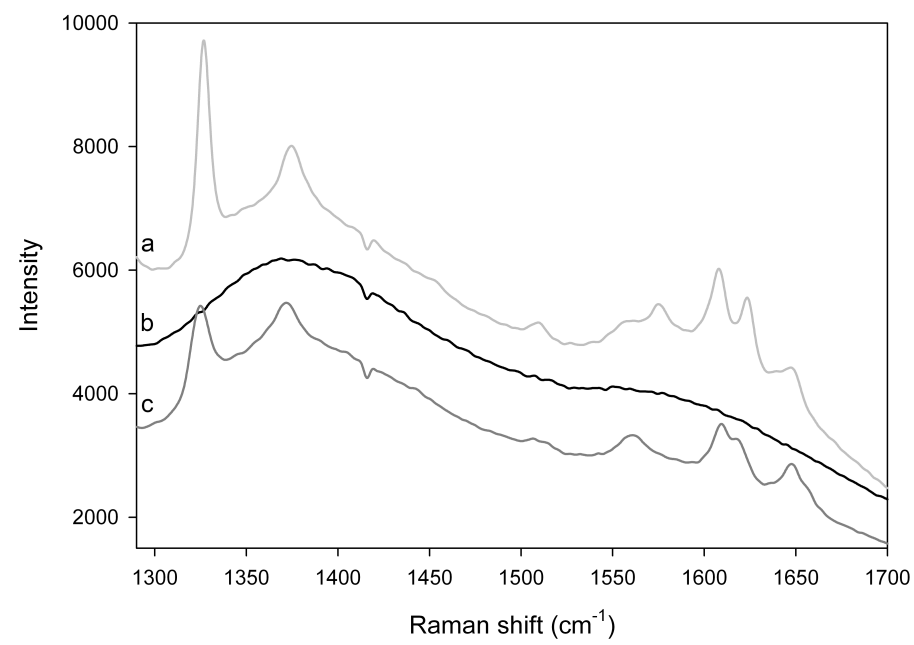




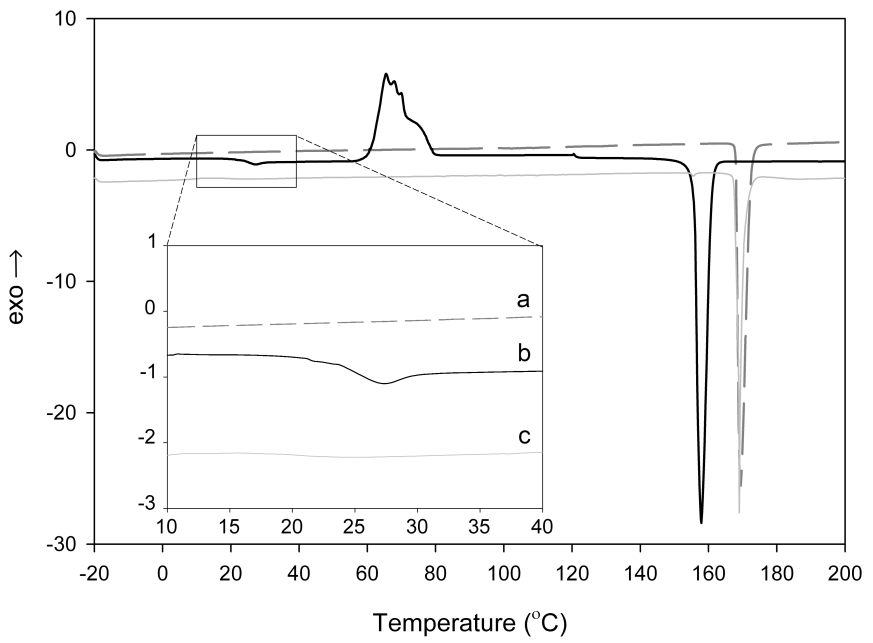




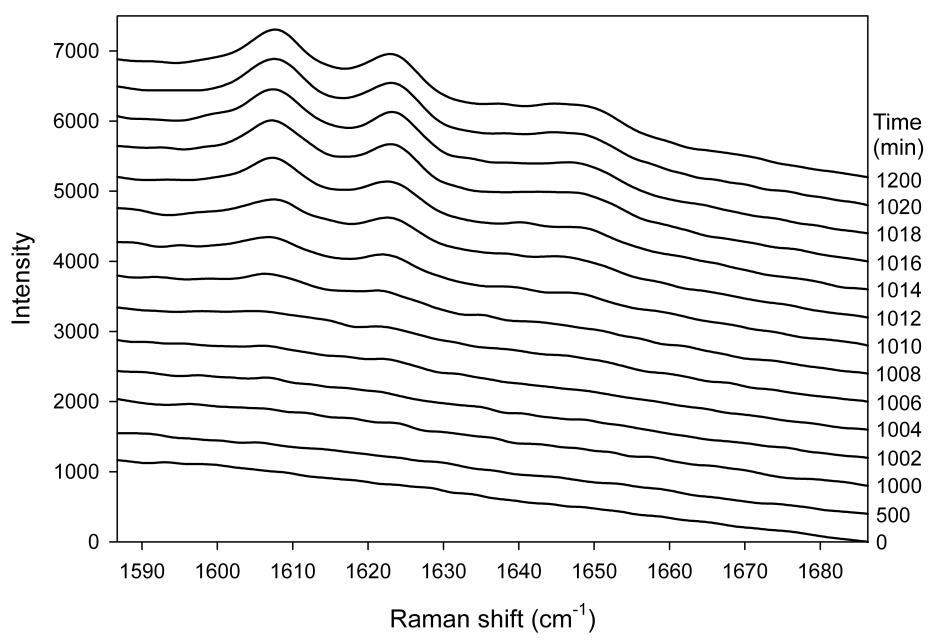


ACCEPTED MANUSCRIPT
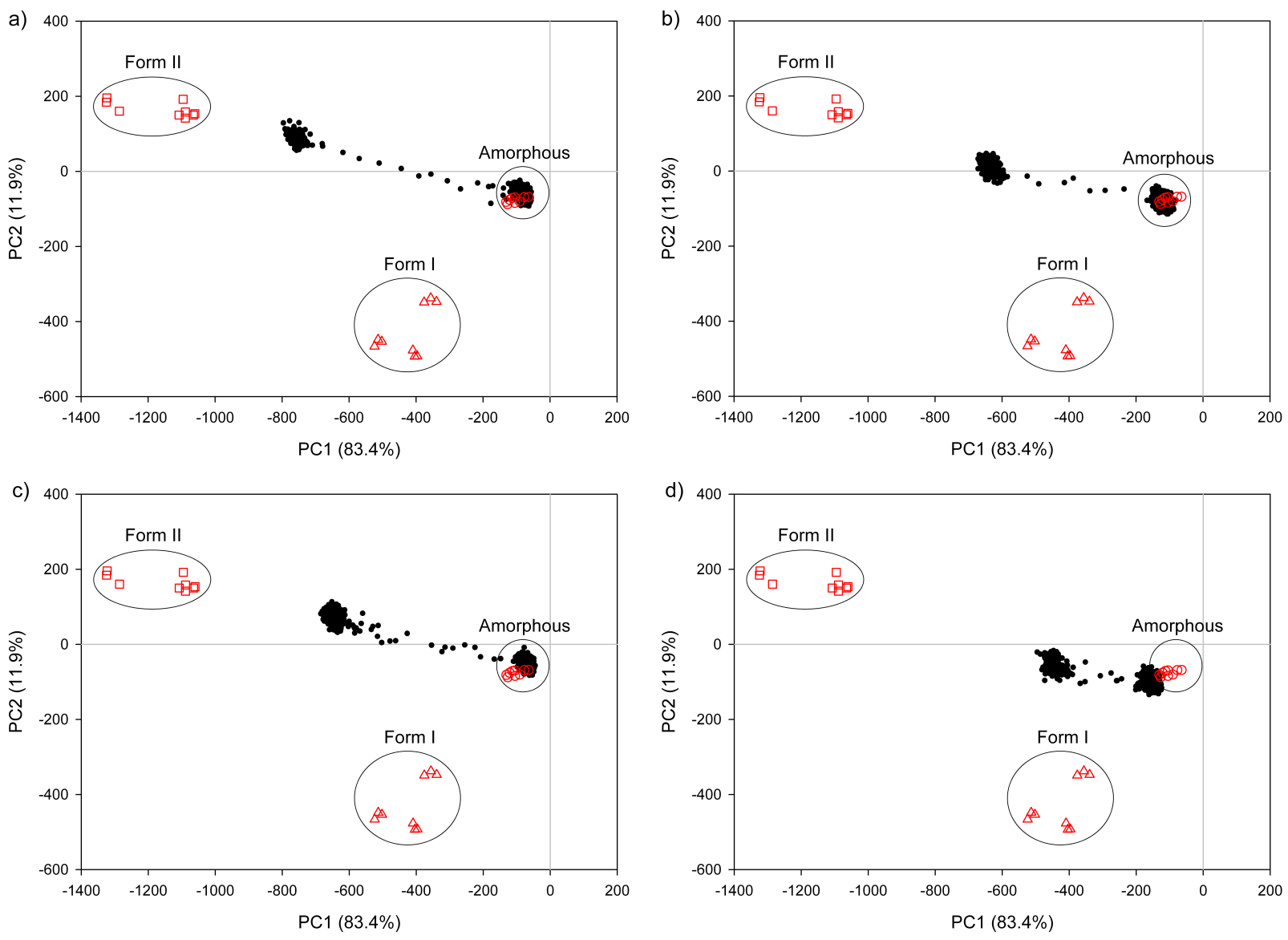

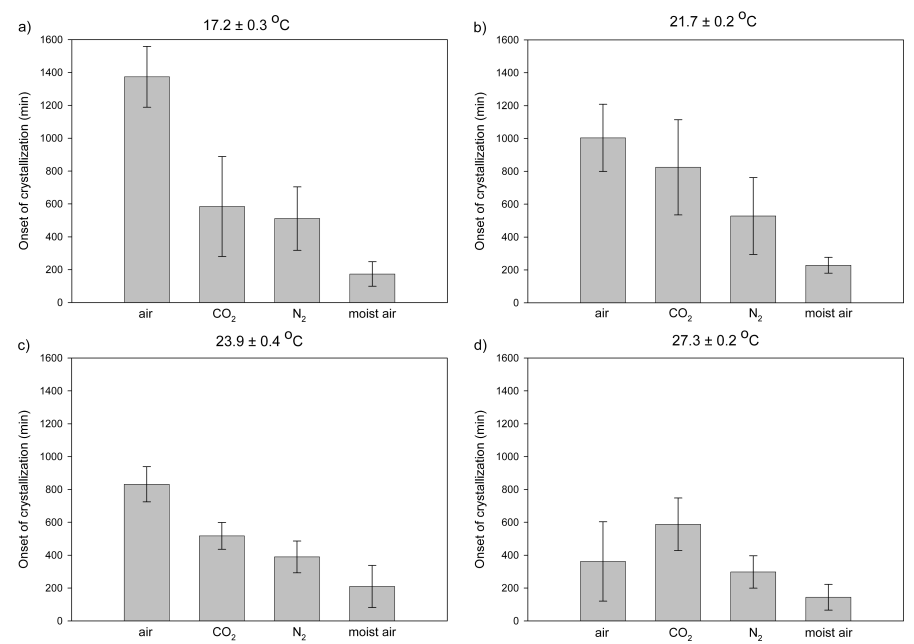


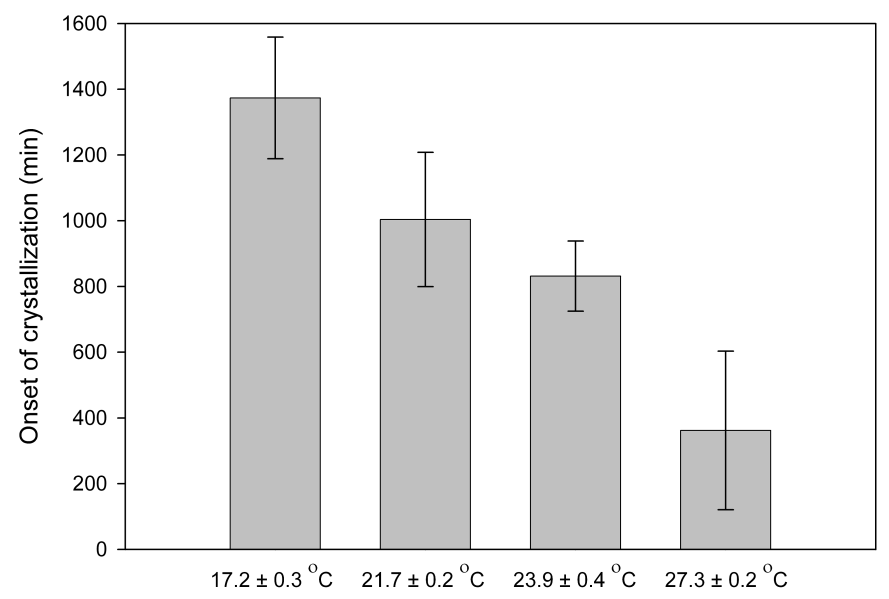




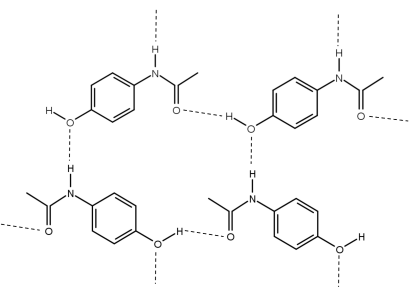

